\title{
Expression and significance of EGFR in malignant peripheral nerve sheath tumor
}

\author{
Daniel Keizman · Josephine Issakov · Isaac Meller • \\ Natalie Maimon · Maya Ish-Shalom · Osnat Sher • \\ Ofer Merimsky
}

Published online: 5 August 2009

(C) Springer Science+Business Media, LLC. 2009

\section{Erratum to: J Neurooncol}

\section{DOI 10.1007/s11060-009-9862-z}

The fourth author's family name was misspelled in the original publication. It is correctly shown in this erratum.

The online version of the original article can be found under doi:10.1007/s11060-009-9862-z.

D. Keizman · N. Maimon · O. Merimsky ( $\varangle)$

Unit of Bone and Soft Tissue Oncology, Division of Oncology,

Tel Aviv Sourasky Medical Center (TASMC), Affiliated with

Sackler School of Medicine, Tel-Aviv University, 6 Weizmann

Street, 64239 Tel Aviv, Israel

e-mail: Merimsky@zahav.net.il

J. Issakov $\cdot$ O. Sher

Unit of Bone and Soft Tissue Pathology, Tel Aviv Sourasky Medical Center (TASMC), Affiliated with Sackler School of

Medicine, Tel-Aviv University, Tel Aviv, Israel

I. Meller

The National Unit of Orthopedic Oncology, Tel Aviv Sourasky Medical Center (TASMC), Affiliated with Sackler School of

Medicine, Tel-Aviv University, Tel Aviv, Israel

\section{Ish-Shalom}

Department of Endocrinology, Tel Aviv Sourasky Medical Center (TASMC), Affiliated with Sackler School of Medicine,

Tel-Aviv University, Tel Aviv, Israel 